\title{
Erratum to: Effectiveness of Risk-Needs-Responsivity-Based Family Violence Programs with Male Offenders
}

\author{
Lynn A. Stewart ${ }^{1}$ - Natalie Gabora ${ }^{1} \cdot$ P. Randall Kropp ${ }^{2} \cdot$ Zina Lee $^{3}$
}

Published online: 17 April 2015

(C) Springer Science+Business Media New York 2015

Erratum to: J Fam Viol (2014) 29:151-164

DOI 10.1007/s10896-013-9575-0

In the article "Effectiveness of Risk-Needs-ResponsivityBased Family Violence Programs with Male Offenders" by Lynn A. Stewart, Natalie Gabora, P. Randall Kropp, and Zina Lee (DOI 10.1007/s10896-013-9575-0) published in Journal of Family Violence 29: 151-164, referenced author Kenneth Corvo's name appears incorrectly as "Corco" on page 152 and in the reference list. The authors apologize for this oversight.

The online version of the original article can be found at http://dx.doi.org/ 10.1007/s10896-013-9575-0.

Lynn A. Stewart

lynn_stewart@sympatico.ca

1 Research Branch, Correctional Service Canada, 340 Laurier Ave. West, Ottawa, Ontario K0A 0P9, Canada

2 Forensic Psychiatric Services Commission of British Columbia and Simon Fraser University, Burnaby, BC, Canada

3 School of Criminology and Criminal Justice, University of Fraser Valley, Abbotsford, BC, Canada 